\title{
Science, Society, and Scientific Literacy
}

\section{Kostas Kampourakis ${ }^{1}$}

Published online: 10 August 2019

(C) Springer Nature B.V. 2019

The present volume happens to include several articles related to socio-scientific issues (SSIs), and this prompted me to devote my editorial to this topic. The first point to make is that any consideration of SSIs in science education must be informed by scholarship is HPS. For instance, an informed treatment of SSIs requires a good understanding of scientific argumentation in order for one to argue for or against a particular view. It also requires a good understanding of the nature of scientific explanation, in order for one to be able to evaluate the scientific consensus on the topic (or the lack thereof) and therefore be able to take informed decisions.

So far so good. The big issue now is that whereas there is a lot of science education research on SSIs, I think that the topic has not been given the required attention in schools. Whereas SSIs could, and in my view should, form the backbone of science education curricula, they are rather treated as special topics. Let me explain. Most science curricula include topics such as mechanics and electromagnetism; the periodic table and chemical reactions; cell biology and metabolism; plate tectonics and volcanoes. These, and other topics, are considered as essential knowledge that students should have, on the one hand because they are among the fundamentals of science and on the other hand because they pertain to socially relevant issues. A typical argument that I have heard from science educators and teachers is that students need to acquire specific knowledge, the alphabet of science according to some of them, as well as specific habits of mind before thinking about the societal relevance of science and about how to deal with SSIs.

However, I am inclined to think that science curricula should be designed the other way around. Rather than thinking which topics are fundamental in some normative sense, and then which ones are socially relevant, SSIs could be given the priority in curriculum design. In other words, science curricula, especially in the higher secondary grades, should consist of SSIs so that students would be taught both about the major issues at stake and the relevant science. If we all agree that the main aim of science education at schools is to educate the citizens of the future, whom we want to be literate about science, and not future scientists, then why aren't SSIs the top priority in science curricula? Even though we are now in the 21st century, we are still teaching students the science of the 19th and the 20th century, because we consider it fundamental. But is it really?

Kostas Kampourakis

Kostas.Kampourakis@unige.ch

1 Section of Biology and IUFE, University of Geneva, Geneva, Switzerland 
Let me explain why I think it is not. If you look at newspapers, or turn on your TV, you will likely come across astrology. You will read or listen to someone making predictions about the future based, more or less, on the month when you were born. There are people who take these arguments seriously and who even pay to get the relevant information. This raises the question: how many physics teachers address this topic at schools? Why should not they? How about more serious issues such as vaccination and the resistance to it? How much time do biology teachers devote to explaining not only how vaccines work, but also that most of the arguments of anti-vaxxers are unfounded? How many teachers show to their students the scientific evidence that the benefits of vaccination outweigh the risks (that do exist in some cases) so that their students decide to vaccinate their children a decade or so later?

I could go on and on with examples like this, but I think I have made my point. There are important topics such the aforementioned ones, as well as climate change, various forms of pollution, genetically modified organisms, and more that could form the basis for sociallyrelevant science teaching, which could educate the scientifically literate citizens of the future. The science that all of us need to understand is first and foremost the one that is relevant to our lives. If students keep learning boring and useless science at schools, they will keep wondering "Why do I need to know that?" And because they ask this question, we had better teach them the science that makes the answer self-evident: "Because it is useful for your life."

\section{Compliance with Ethical Standards}

Conflict of Interest The author declares no conflict of interest.

Publisher's Note Springer Nature remains neutral with regard to jurisdictional claims in published maps and institutional affiliations. 